\title{
Development and Evaluation of Near-Isogenic Lines with Different Blast Resistance Alleles at the Piz Locus in japonica Rice from the Lower Region of the Yangtze River, China
}

Yunyu Wu, Lixiahe Agricultural Research Institute of Jiangsu Province, Yangzhou 225009, China; and Jiangsu Collaborative Innovation Center for Modern Crop Production, Nanjing 210095, China; Yu Chen, Lixiahe Agricultural Research Institute of Jiangsu Province, Yangzhou; Jiangsu Collaborative Innovation Center for Modern Crop Production, Nanjing; and Key Laboratory of Plant Functional Genomics, Ministry of Education, Yangzhou University, Yangzhou, 225009, China; Cunhong Pan, Ning Xiao, Ling Yu, Yuhong Li, and Xiaoxiang Zhang, Lixiahe Agricultural Research Institute of Jiangsu Province, Yangzhou and Jiangsu Collaborative Innovation Center for Modern Crop Production, Nanjing; Xuebiao Pan and Xijun Chen, Key Laboratory of Plant Functional Genomics, Ministry of Education, Yangzhou University, Yangzhou; Chengzhi Liang, Institute of Genetics and Developmental Biology, Chinese Academy of Sciences, Beijing 100101, China; and Zhengyuan Dai and Aihong Li, Lixiahe Agricultural Research Institute of Jiangsu Province, Yangzhou 225009, China; and Jiangsu Collaborative Innovation Center for Modern Crop Production, Nanjing 210095, China

\begin{abstract}
Rice blast, caused by Magnaporthe oryzae, threatens rice production in most of the rice-growing areas in China, especially in regions that have grown Oryza sativa subsp. japonica in recent years. The use of resistance genes is the most effective and economical approach for blast control. In our study, a set of six near-isogenic lines (NIL) were developed by introgression of six resistance alleles of the Piz locus (Pi2, Pigm, Pi40, Pi9, $P i z$, and $P i z t$ ) into a blast-susceptible, high-yielding, high-quality japonica '07GY31' via marker-assisted backcross breeding. Artificial inoculation using $144 \mathrm{M}$. oryzae isolates collected from the lower region of the Yangtze River, China, revealed that most of the NIL, including NIL-Pi2, NIL-Pigm, NIL-Pi40, NIL-Pi9, and NIL-Pizt, exhibited broad-spectrum resistance against rice blast at the seedling stage, with resistance frequencies (RF)

of 93.06 to $98.61 \%$. NIL-Piz was an exception, with an RF of $21.53 \%$, which was slightly higher than the recurrent parent 07GY31. NIL-Pi40 and NIL-Pigm had broad-spectrum resistance (RF of 93.33 and $71.67 \%$, respectively) at the heading stage following inoculation of 60 isolates of M. oryzae. Field trials with artificial inoculation at the seedling and heading stage showed that NIL-Pigm and NIL-Pi4O were highly resistant in four locations under high disease pressure. NIL-Pizt showed effective resistance in three locations from Zhejiang and Jiangsu Provinces. This study shows that $O$. sativa subsp. japonica alleles of the Piz locus confer resistance to M. oryzae, and provides an effective method to enhance seedling and panicle blast resistance in rice plants in the lower region of the Yangtze River, China.
\end{abstract}

Rice blast, caused by the fungus Magnaporthe oryzae, is one of the most destructive diseases worldwide, resulting in considerable economic damage (Dean et al. 2005). Outbreaks of rice blast have been severe in Southeast Asian countries, including India, Indonesia, Vietnam, and the Philippines. For example, in an average year, M. oryzae causes a $50 \%$ loss in rice yield in upland regions of eastern India (Khush and Jena 2009; Liu et al. 2010a). In recent years, approximately 5.33 million ha of rice have been impacted by rice blast, resulting in losses of 1.5 million tons in China alone (He et al. 2014). Effective strategies to control rice blast are urgently needed to ensure global food security.

The most effective and economical approach to manage rice blast is to develop cultivars which have resistance $(R)$ genes. Approximately $100 R$ genes conferring resistance against various isolates of $M$. oryzae have been identified (Sharma et al. 2012) and $28 R$ genes, including Pit, Pish, Pi35, Pi37, Pi64, Pib, pi21, Pi63, Pid2, Pid3, Pi25, Pi2, Pi9, Pi50, Pigm, Pi36, Pi5, Pia/Pi-CO39, Pil, Pi54/Pi54rh, Pikm, Pikp, Pik, Pbl, and Pita, have been characterized molecularly (Ashkani et al. 2016; Deng et al. 2017; Fukuoka et al. 2014; Ma et al. 2015; $\mathrm{Su}$ et al. 2015; Xu et al. 2014). Whole-genome sequencing and functional genomics facilitate the identification of molecular markers associated with $R$ genes, and several $R$ genes have already been incorporated into rice cultivars using marker-assisted backcross breeding (MABB) (Divya et al. 2014; A. K. Singh et al. 2015; V. K. Singh et al. 2012).

Corresponding author: A. Li; E-mail: yzlah@126.com

*The $\boldsymbol{e}$-Xtra logo stands for "electronic extra" and indicates that one supplementary table is published online.

Accepted for publication 17 March 2017.

(c) 2017 The American Phytopathological Society
Under favorable environmental conditions (moderate temperatures and high relative humidity), $M$. oryzae can completely destroy seedlings in nurseries (seedling blast) and crops at the heading stage (panicle blast). Seedling blast increases plant respiration and reduces the maximum photosynthetic rate at light saturation (Pinnschmidt et al. 1994), resulting in stunted plants, reduction in the number of bearing panicles, and reduction in the weight of individual grains (Thruston 1998). At the heading stage, infected stem nodes and panicles result in barren panicles, chalky kernels, and sterile grain (Candole et al. 1999). The timeconsuming and cumbersome nature of inoculating rice panicles with $M$. oryzae has limited the focus of most studies to seedling blast resistance (Hao et al. 2011). However, rice panicle blast, which directly reduces the percentage of grain filling, grain weight, and grain quality, is the major cause of yield loss (Titone et al. 2015). The specific genetic mechanisms of resistance to seedling blast and panicle blast may be varied and independently controlled by different $R$ genes (Sirithunya et al. 2002). Therefore, evaluation of blast-resistant genes focusing only on seedling blast and ignoring panicle blast is incomplete and could result in yield loss if only seedling blast resistance cultivars were produced.

Oryza sativa subsp. japonica rice has always been an important food source in China (Zhang et al. 2012). Excellent grain quality and palatability of japonica rice has resulted in an increase in planting area, especially in Jiangsu Province (JS). In recent years, the rice planting area in JS was about 2.2 million ha, of which more than $85 \%$ was planted with cultivars of japonica rice, accounting for $20 \%$ of the total japonica planted area and 30\% of total japonica rice production in China (Deng and Du 2006; Zhang et al. 2011). Many high-yielding japonica cultivars have been released that include one or more of the blast-resistant genes Pish, Pib, Piz, Pi54, Pikm, and Pita (Fan et al. 2014; $\mathrm{Wu}$ et al. 2015b). However, due to genetic variation of the pathogen, many japonica cultivars have lost their resistance and severe blast disease outbreaks are occurring more frequently. Environmental conditions are also important. In 2014 in JS, 60 to $70 \%$ of 
japonica rice fields were affected by panicle blast due to greater rainfall and lower temperature from the booting stage to the grain-filling stage (He et al. 2015; Wei and Song 2014). Therefore, it is imperative to analyze blast races isolated from diseased panicles for identifying the prevalent races responsible for the epidemics and to introduce new and effective $R$ genes resistant to those races. Using MABB, we generated a set of near-isogenic lines (NIL), each with one of the rice blast resistance alleles Pi2, Pigm, Pi40, Pi9, Piz, and Pizt at the Piz locus in the genetic background of '07GY31'. We evaluated the resistance of NIL with multialleles of Piz locus though artificial inoculation assays and field tests in four blast nurseries, and assessed the agronomic and grain quality of the lines. The above results are expected to guide rational utilization of multialleles of the Piz locus in japonica background and provide broad-spectrum and effective resistance materials for improving resistance against $M$. oryzae predominant in the lower region of the Yangtze River, China.

\section{Materials and Methods}

Plant materials and pathogens. Six $O$. sativa lines- 'C101A51' (Pi2), 'Gumei 4' (Pigm), 'IR65482' (Pi40), '75-1-127' (Pi9), 'Fukunishiki' (Piz), and 'Toride 1' (Pizt) — which carry different $R$ genes were used as donors in this study. $F_{1}$ generations derived from crosses between donors of the $R$ genes and 07GY31 were screened for the presence of target $R$ genes using tightly linked markers to identify plants with heterozygous amplification patterns. Individual plants heterozygous at the target locus were backcrossed with $07 \mathrm{GY} 31$ to generate $\mathrm{BC}_{1} \mathrm{~F}_{1}$ populations. Foreground selection was carried out on $>100$ plants at each generation by molecular markers, and agromorphological resemblance to the recurrent parent was used to identify $\mathrm{BC}_{\mathrm{n}} \mathrm{F}_{1}$ plants heterozygous at the target locus with a phenotype similar to the recurrent parent $07 \mathrm{GY} 31$. The $\mathrm{BC}_{6} \mathrm{~F}_{4}$ generation was produced by successive backcrossing with the recurrent parent and selfing of selected plants. Finally, 8 to 10 homozygous lines of each $R$ gene with agronomic traits similar to those of $07 \mathrm{GY} 31$ were developed (Fig. $1 A)$. All homozygous $R$-gene lines were examined for recurrent parent genome (RPG) recovery using the genotyping by sequencing (GBS) method (Chen et al. 2014). Lines with maximum RPG recovery were selected and designated as NIL-Pi2, NIL-Pigm, NIL-Pi40, NIL-Pi9, NIL-Piz, and NIL-Pizt.

A set of seven Chinese differential rice cultivars-'Tetep', 'Zhenglong 13', 'Sifeng 43', 'Dongnong 363', 'Kanto 51', 'Hejiang 18', and 'Lijangxintuanheigu' (LTH) - were used to study pathogenicity and subgroups of isolates of $M$. oryzae at the seedling stage (Ling et al. 2004). In total, 144 isolates of $M$. oryzae were collected and obtained from diseased panicles from different parts of infected fields in various counties of JS and Anhui (AH), Hubei (HB), and Zhejiang (ZJ) Provinces. Single-spore isolation, strain cultivation, and inoculum preparation were conducted as reported by Puri et al. (2009).

Molecular marker assay. DNA isolation and polymerase chain reaction conditions. Three-week-old rice leaves were collected from plants, immediately frozen in liquid nitrogen, and stored at $-80^{\circ} \mathrm{C}$ until DNA extraction. Genomic DNA was extracted using the tris physiological saline (TPS) rapid extraction method (Lu and Zheng 1992), diluted with Tris-EDTA buffer (10 mM Tris- $\mathrm{HCl}$ [pH 8.00 and $0.1 \mathrm{mM}$ EDTA) to $100 \mathrm{ng} \mu \mathrm{l}^{-1}$, and stored at $-20^{\circ} \mathrm{C}$. Polymerase chain reaction (PCR) amplification was carried out in a $20-\mu 1$ reaction mixture containing $2.0 \mu \mathrm{l}$ of $\mathrm{MgCl}_{2}\left(25 \mathrm{mmol}\right.$ liter $\left.^{-1}\right), 2.0 \mu \mathrm{l}$ of $10 \times$ PCR buffer, $1.5 \mu \mathrm{l}$ of each primer $\left(10 \mu \mathrm{mol} \mathrm{liter}{ }^{-1}\right), 50 \mathrm{ng}$ of DNA template, $0.2 \mu \mathrm{l}$ of

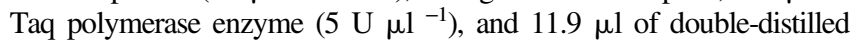
$\mathrm{H}_{2} \mathrm{O}$. Amplification included a predenaturation for $5 \mathrm{~min}$ at $94^{\circ} \mathrm{C}$; followed by 35 cycles of $45 \mathrm{~s}$ at $94^{\circ} \mathrm{C}, 45 \mathrm{~s}$ at the annealing temperature (Supplementary Table S1), and $1 \mathrm{~min}$ at $72^{\circ} \mathrm{C}$; and a final extension of $10 \mathrm{~min}$ at $72^{\circ} \mathrm{C}$. The PCR products were separated by electrophoresis on $4 \%$ agarose gels with ethidium bromide and photographed under ultraviolet light using a gel documentation system (Bio-Rad).

Foreground selection by molecular markers. The molecular markers AP22, Z4794, and ZJ58.7, linked to blast $R$ genes $P i 2$ and Pigm (Koide et al. 2009; Yu et al. 2013), were used to select the foreground of backcrossed and selfed generations. Detailed information describing target gene markers is provided in Supplementary Table S1.

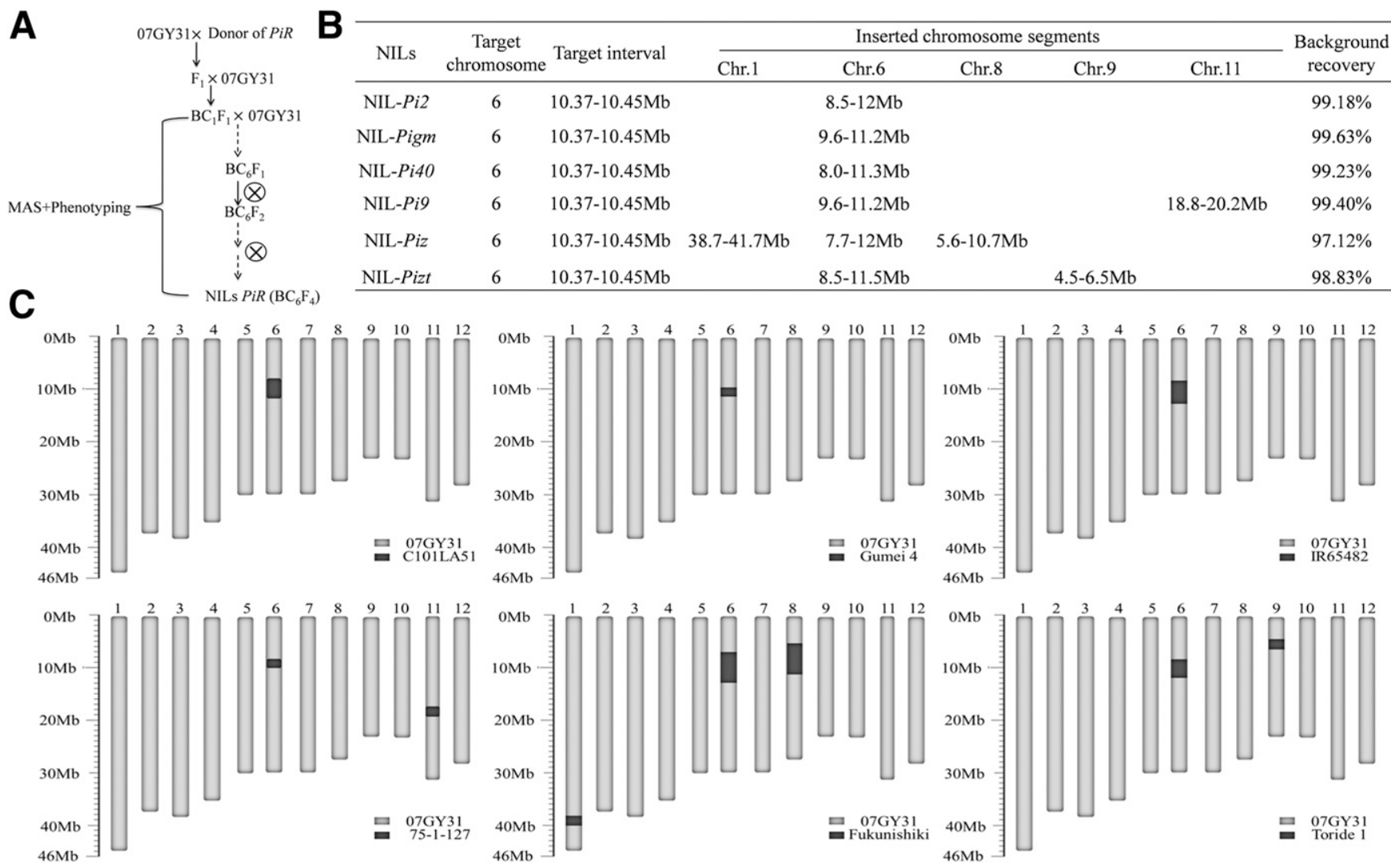

Fig. 1. Construction of near-isogenic lines (NIL) with target genes in the genetic background of japonica 07GY31. A, Scheme showing the construction of NIL carrying target genes. B, Recurrent parent genome recovery of PiR NIL. C, Donor chromosome segment inserted in PiR NIL. 
GBS background analysis. Genomic DNA was extracted from $100 \mathrm{mg}$ of leaf tissue using DNAsecure Plant kit reagents (Qiagen). The quality of extracted genomic DNA was measured using BioPhotometer plus (Eppendorf). Genomic DNA was digested with restriction enzymes BamHI and $M s p I$ and sequencing libraries were constructed as described by Poland et al. (2012) using an Illumina HiSeq 2000 Sequencer (Illumina). The raw Illumina DNA sequence data (FASTQ file) were processed through the GBS analysis pipeline as implemented in TASSEL v3.0 software (Bradbury et al. 2007). The filtered sequence reads were aligned to the already available draft genome sequence of 'Nipponbare' rice using the Burrows-Wheeler alignment tool (Li and Durbin 2009). Further, single-nucleotide polymorphisms and genotyping were called using a minor allele frequency $>0.05$ (Guajardo et al. 2015).

Evaluation for blast resistance. Evaluation for blast resistance by artificial inoculation. All six NIL and seven Chinese differential rice cultivars were screened for seedling blast resistance by artificial inoculation at the seedling stage with the $144 \mathrm{M}$. oryzae isolates. Ten plants of each tested materials were grown in a plastic tray ( 60 by 30 by $4 \mathrm{~cm}$ ) filled with sieved garden soil in a greenhouse maintained at 27 to $30^{\circ} \mathrm{C}$. Each tray contained the six NIL, recurrent parent $07 \mathrm{GY} 31$, and the seven cultivars of Chinese differential rice cultivars, with the highly susceptible LTH as the susceptible control. There were three replicate trays for each $M$. oryzae isolate (432 trays in total), with a tray for a blast isolate inoculation. Three-week-old rice seedlings (in the growth stage $\mathrm{BBCH} 14$ to 15) were inoculated with $40 \mathrm{ml}$ of an $M$. oryzae conidial suspension $\left(5 \times 10^{4}\right.$ conidia $\left./ \mathrm{ml}\right)$ with $0.02 \%$ Tween 20 using a hand atomizer $(100 \mathrm{kPa})$ connected to an air compressor. Inoculated plants were incubated for $24 \mathrm{~h}$ in the dark in growth chambers maintained at $26^{\circ} \mathrm{C}$. Plants were transferred to the greenhouse postinoculation under a photocycle of $12 \mathrm{~h}$ of light and $12 \mathrm{~h}$ of darkness at 80 to $90 \%$ relative humidity by intermittently spraying water for 1 to 2 min every $2 \mathrm{~h}$. Disease severity was recorded 7 days postinoculation using a 0-to-5 disease-scoring scale according to standard procedures (Mackill and Bonman 1992), where lines with scores of 0 to 2 were considered resistant (R) and 3 to 5 were considered susceptible (S). Resistance was represented by resistance frequency $(\mathrm{RF})$, defined as $\mathrm{RF}=$ (number of incompatible $M$. oryzae isolates/total number of $M$. oryzae isolates inoculated $) \times 100 \%(\mathrm{Wu}$ et al. $2015 \mathrm{~b})$.

The NIL and recurrent parent were screened for resistance to panicle blast under natural conditions. Due to the large amount of work necessary to inoculate at the heading stage, a set of 60 isolates was selected from the set of 144 blast isolates. Selection criteria were based on the virulence patterns in seven Chinese differential rice cultivars, as described by Wu et al. (2016). Plants were transplanted into a paddy field three times at 10-day intervals to ensure that selected rice tillers were uniform and in the same developmental stage at inoculation time. Each plot contained 10 rows and 20 plants per row, with row spacing of 13.3 by $25 \mathrm{~cm}$. A randomized complete block design (RCBD) was used with three replications. Individual rice tillers were inoculated in the growth stage $\mathrm{BBCH} 51$ (the beginning of panicle initiation) by injecting $1 \mathrm{ml}$ of an M. oryzae conidial suspension $\left(5 \times 10^{4}\right.$ conidia/ml $)$ into the panicle of each plant in the rows between the second and ninth rows. In total, 10 rice tillers were inoculated with each $M$. oryzae isolate. In the ripe stage (40 to 50 days after heading), panicle blast evaluation was based on panicle blast symptoms and the standard reference was described by Puri et al. (2009).

Multilocation disease resistance evaluations in the blast nurseries. The NIL and recurrent parent were screened in blast nurseries at four locations with high disease pressure: Xinyi and

Table 1. Information of Magnaporthe oryzae races collected from 30 counties in the lower Yangtze region in 2014

\begin{tabular}{|c|c|c|c|}
\hline Province, county & $N^{\mathbf{z}}$ & Subgroup & Race \\
\hline \multicolumn{4}{|l|}{ Jiangsu (JS) } \\
\hline Xuzhou (XZ) & 4 & $\mathrm{ZG}$ & ZG1 (4) \\
\hline Ganyu (GY) & 5 & $\mathrm{ZG}, \mathrm{ZH}$ & ZG1 (4), ZH (1) \\
\hline Donghai (DH) & 5 & $\mathrm{ZE}, \mathrm{ZG}$ & ZE3 (1), ZG1 (4) \\
\hline Suining (SN) & 5 & $\mathrm{ZC}, \mathrm{ZE}, \mathrm{ZG}$ & ZC15 (1), ZE3 (2), ZG1 (2) \\
\hline Suqian (SQ) & 5 & $\mathrm{ZC}, \mathrm{ZG}$ & ZC15 (2), ZG1 (3) \\
\hline Binhai $(\mathrm{BH})$ & 4 & $\mathrm{ZG}$ & ZG1 (4) \\
\hline Xuyi (XY) & 5 & $\mathrm{ZD}, \mathrm{ZG}$ & ZD7 (2), ZG1 (3) \\
\hline Baoying (BY) & 6 & $\mathrm{ZA}, \mathrm{ZE}, \mathrm{ZD}, \mathrm{ZG}$ & ZA59 (1), ZE1 (2), ZD5 (1), ZG1 (2) \\
\hline Yandu (YD) & 5 & $\mathrm{ZB}, \mathrm{ZC}, \mathrm{ZF}, \mathrm{ZG}$ & ZB31 (1), ZC15 (2), ZF1 (1), ZG1 (1) \\
\hline Xinghua (XH) & 4 & $\mathrm{ZE}, \mathrm{ZG}$ & ZE1 (1), ZG1 (3) \\
\hline Xingtai (XT) & 4 & $\mathrm{ZE}, \mathrm{ZG}$ & ZE1 (3), ZG1 (1) \\
\hline Jiangdu (JD) & 5 & $\mathrm{ZC}, \mathrm{ZD}, \mathrm{ZG}$ & ZC15 (2), ZD7 (1), ZG1 (2) \\
\hline Rugao (RG) & 5 & $\mathrm{ZC}, \mathrm{ZG}$ & ZC15 (2), ZG1 (3) \\
\hline Jingjiang (JJ) & 3 & $\mathrm{ZG}, \mathrm{ZH}$ & ZG1 (2), ZH (1) \\
\hline Zhenjiang (ZJ) & 5 & $\mathrm{ZG}$ & ZG1 (5) \\
\hline Jurong (JR) & 4 & $\mathrm{ZC}, \mathrm{ZG}$ & ZC15 (1), ZG1 (3) \\
\hline Wujin (WJ) & 5 & $\mathrm{ZC}, \mathrm{ZG}$ & ZC15 (1), ZG1 (4) \\
\hline Tongzhou (TZ) & 5 & $\mathrm{ZG}$ & ZG1 (5) \\
\hline \multicolumn{4}{|l|}{ Anhui (AH) } \\
\hline Lujiang (LJ) & 6 & $\mathrm{ZA}, \mathrm{ZB}, \mathrm{ZD}, \mathrm{ZG}$ & ZA57 (2), ZB15 (2), ZD7 (1), ZG1 (1) \\
\hline Huaibei (HB) & 4 & $\mathrm{ZA}, \mathrm{ZC}, \mathrm{ZG}$ & ZA15 (1), ZC15 (2), ZG1 (1) \\
\hline Chuzhou (CZ) & 5 & $\mathrm{ZB}, \mathrm{ZD}, \mathrm{ZE}, \mathrm{ZH}$ & ZB15 (2), ZD7 (1), ZE1(1), ZH (1) \\
\hline Wuhu (WH) & 5 & $\mathrm{ZB}, \mathrm{ZF}, \mathrm{ZG}$ & ZB15 (1), ZB31 (1), ZF1 (1), ZG1(2) \\
\hline \multicolumn{4}{|l|}{ Hubei (HB) } \\
\hline Xianning (XN) & 4 & $\mathrm{ZA}, \mathrm{ZC}$ & ZA15 (1), ZA63 (1),ZC15 (2) \\
\hline Huanggang (HG) & 5 & $\mathrm{ZA}, \mathrm{ZC}, \mathrm{ZE}, \mathrm{ZH}$ & ZA49 (1), ZC15 (2), ZE1 (1), ZH (1) \\
\hline Huangmei (HM) & 5 & $\mathrm{ZB}, \mathrm{ZD}, \mathrm{ZF}, \mathrm{ZH}$ & ZB31 (2), ZD5 (1), ZF1 (1), ZH (1) \\
\hline Macheng (MC) & 6 & $\mathrm{ZB}, \mathrm{ZC}, \mathrm{ZD}, \mathrm{ZG}$ & ZB29 (1), ZB31 (1), ZC15 (2), ZD7 (1), ZG1(1) \\
\hline \multicolumn{4}{|l|}{ Zheiiang (ZJ) } \\
\hline Changxin (CX) & 5 & $\mathrm{ZC}, \mathrm{ZE}, \mathrm{ZG}$ & ZC7 (1), ZE1 (2), ZG1 (2) \\
\hline Fuyang (FY) & 5 & $\mathrm{ZC}, \mathrm{ZF}, \mathrm{ZG}$ & ZC11 (1), ZF1 (1), ZG1 (3) \\
\hline Shaoxing (SX) & 5 & $\mathrm{ZC}, \mathrm{ZF}, \mathrm{ZG}$ & ZC15 (2), ZF1 (1), ZG1 (2) \\
\hline Ningbo (NB) & 5 & $\mathrm{ZD}, \mathrm{ZG}, \mathrm{ZH}$ & ZD3 (1), ZG1 (3), ZH (1) \\
\hline
\end{tabular}

${ }^{\mathrm{z}}$ Number of isolates. 
Jintan cities, JS; Lujiang County, AH; and Changxin County, ZJ. Each field location had five rows, 12 plants per row (with row spacing of 13.3 by $25 \mathrm{~cm}$ ), and three replications in a RCBD. To ensure uniform spread of $M$. oryzae, a row of a susceptible cultivar was planted every five rows and on the borders of the fields. Seedling blast was evaluated at seedling stage and panicle blast disease evaluation was done on a 0 to-9 standard evaluation scale of IRRI (2002) at ripe stage. NIL with a score of 0 to 1 score were considered highly resistant (HR), 2 to 3 were $\mathrm{R}, 4$ were moderately resistant (MR), 5 to 6 were moderately susceptible (MS), 7 were S, and 8 to 9 were highly susceptible (HS) (Wu et al. 2016). Scores were subjected to location-wise RCBD analysis and genotype + genotype-environment interaction (GGE) biplot-based stability analysis using Genstat v.18 (Ellur et al. 2016; Yan 2010).

Evaluation of agronomic and grain quality traits of NIL. The NIL and the recurrent parent were planted in the field at Lixiahe Agricultural Research Institute, JS, China (32 $\left.38^{\prime} \mathrm{N} 119^{\circ} 43^{\prime} \mathrm{E}\right)$, during summer 2015. Plots of seven rows with 12 plants per row were established as described above, with a RCBD and two replications. Agronomic traits were measured according to the standard evaluation system for rice (IRRI 2002). Five plants between the second and sixth rows in each plot were selected for the following agronomic traits: days to $50 \%$ flowering (DFF), plant height $(\mathrm{PH})$, panicle number per plant (PN), total spikelets per plant (TSP), spikelet fertility (SF), 1,000-grain weight $(\mathrm{GW})$, and yield per plant (YPP). Bulk seed harvested from each plant were used to analyze the rice-grain quality traits: brown rice rate, milled rice recovery, rice grain length, grain length-to-width ratio, amylose content, chalkiness rate, chalkiness degree, gel consistency, and alkali digestion value.

Data analysis. Data of seedling blast and panicle blast disease severity and agronomic and grain quality traits were analyzed using Tukey's honestly significant difference test procedure in the SPSS 19.0 program. Multiple comparisons were used to reveal differences among the NIL tested for seedling blast and panicle blast disease severity and agronomic and grain quality traits, where $P \leq 0.05$ was used to measure statistical significance.

\section{Results}

Development of NIL with multiple Piz alleles in the genetic background of japonica 07GY31. The $R$ genes Pi2, Pigm, Pi40, $P i$, Piz, and Pizt were individually introgressed into 07GY31 using a recurrent backcrossing procedure combined with marker-assisted foreground and phenotypic selection. The superior introgression lines were evaluated for RPG recovery using the GBS method. Sequencing results showed that the extent of NIL RPG recovery ranged from $97.12 \%$ in NIL-Piz to $99.63 \%$ in NIL-Pigm (Fig. 1B). All chromosomes in the improved lines, except for the target gene region on chromosome 6 , were almost fully recovered and suitable for comparative analysis (Fig. 1C).

Race composition of $M$. oryzae varied significantly among different rice cultivation areas in the lower region of the Yangtze River, China. The virulence patterns and subgroups of the 144 isolates were evaluated using seven Chinese differential rice cultivars. Results showed that the rice blast isolates were very diverse, with different $\mathrm{R}$ or $\mathrm{S}$ phenotypes observed among the differential rice cultivars. The isolates were classified into eight subgroups with a total of 19 physiological races (Table 1), in which race $\mathrm{ZG}_{1}$ was predominant, with an appearance frequency of $50.00 \%$, followed by race $\mathrm{ZC}_{15}$ at $14.58 \%$. Analysis of the spatial distribution of $M$. oryzae revealed that its population structure varied significantly among different rice cultivation areas in the lower region of the Yangtze River. $M$. oryzae race composition was relatively simple in $\mathrm{JS}$ and $\mathrm{ZJ}$, where race $\mathrm{ZG}_{1}$ predominated, with appearance frequencies of 67.86 and $50.00 \%$, respectively. More complicated race compositions were observed in $\mathrm{AH}$ and $\mathrm{HB}$, where no race predominated. Of the 20 monoconidial isolates collected from each of $\mathrm{AH}$ and $\mathrm{HB}$, there were eight subgroups with 10 to 12 physiological races, respectively (Table 1 ).
A
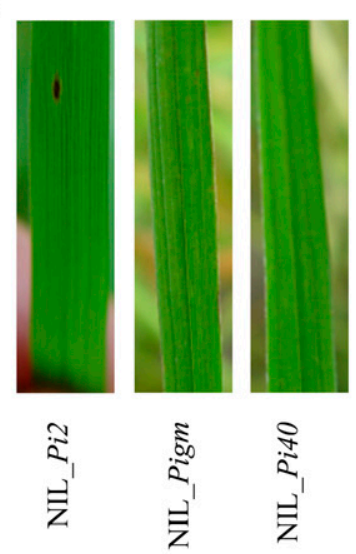
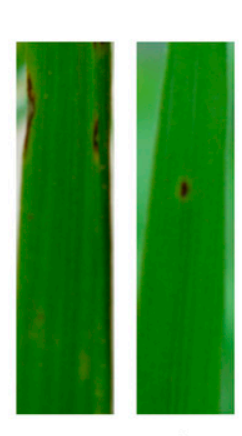

$\frac{2}{\vec{z}}$
Isolate: JSBY4-3

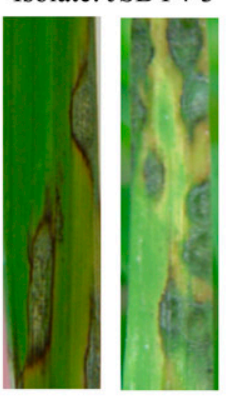

$\begin{array}{ll}\stackrel{N}{2} & \bar{m} \\ \dot{n}^{\prime} & 0\end{array}$
B

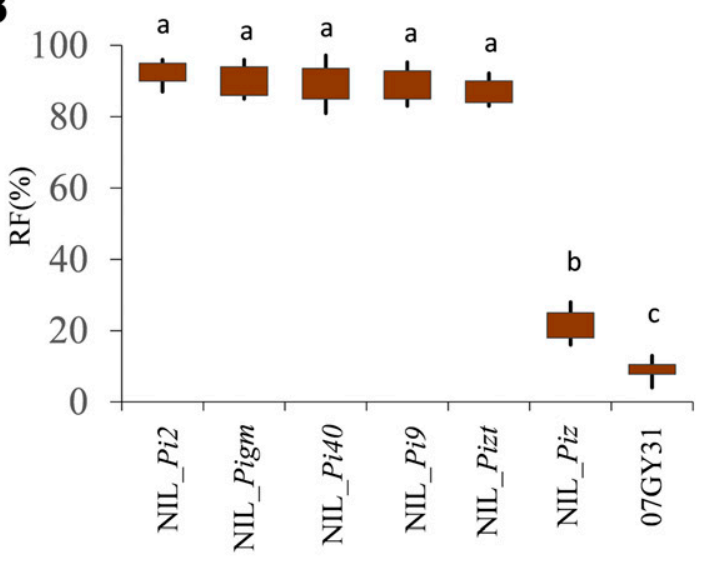

C
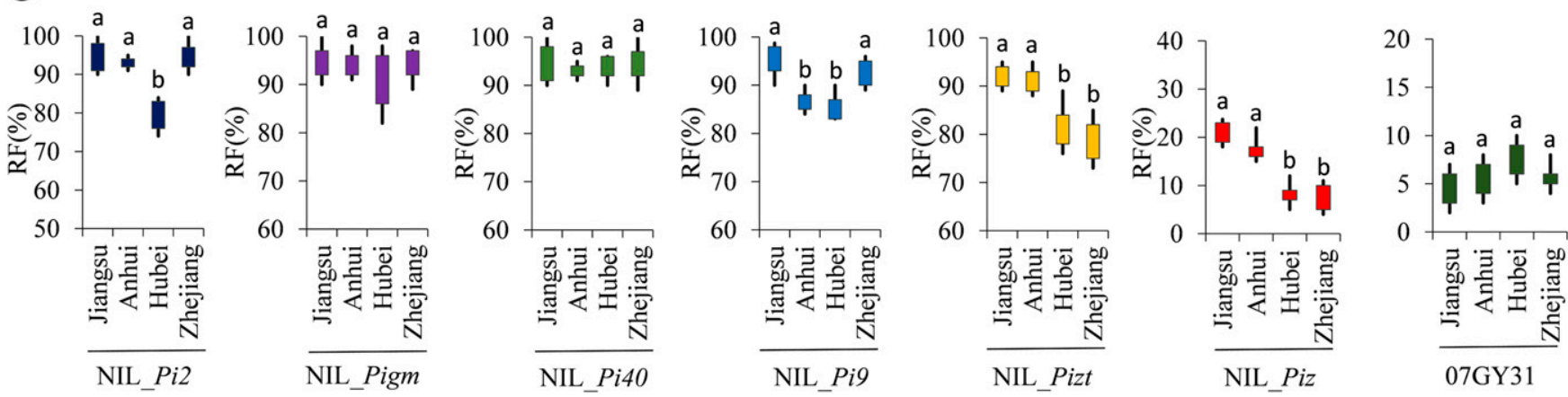

Fig. 2. Blast-resistance scores of improved near-isogenic lines (NIL) and the recurrent parent at the seedling stage. A, NIL disease reactions against a typical blast isolate, JSBY43. B, Resistance characterization of NIL challenged with 144 Magnaporthe oryzae populations. C, Comparison of resistance frequency among improved NIL and the recurrent parent against four $M$. oryzae populations collected in the lower region of the Yangtze River, China. Values labeled with the same letter do not differ significantly according to Tukey's honestly significant difference test at the 0.05 significance level. 
NIL with multiple Piz alleles exhibited different levels of resistance to $M$. oryzae though artificial inoculation. Different resistance patterns against the 144 isolates of $M$. oryzae were exhibited by the NIL and the recurrent parent (Fig. 2A). NIL-Pi2, NIL-Pigm, and NIL-Pi40 showed broad-spectrum resistance to seedling blast, with the highest resistance frequency ranging from 97.92 to $98.61 \%$. NIL-Pi9 and NIL-Pizt were found resistant against 138 and 134 blast isolates with a resistance frequency of 95.83 and $93.06 \%$, respectively. The recurrent parent $07 \mathrm{GY} 31$ was found susceptible to most isolates, with an RF of $7.64 \%$. However, the NIL-Piz was only resistant against 31 isolates, with an RF of $21.53 \%$ (Fig. 2B). When each NIL and the recurrent parent line were examined across the four provinces, most of the RF were not significantly different at $P \leq 0.05$ (Fig. 2C).

Significant differences in patterns of resistance and degrees of susceptibility to panicle blast among the NIL and recurrent parent 07GY31 were observed (Fig. 3A). The panicle blast RF values among the NIL were significantly different from the seedling blast RF values $(P \leq 0.05$; Fig. 3B). The highest level of resistance to panicle blast was exhibited by NIL-Pi40, with an RF of $93.33 \%$, which is equivalent to its resistance level against seedling blast. NIL-Pigm had a panicle blast RF of $71.67 \%$, slightly less than its seedling blast RF value. Panicle blast resistance levels of NIL-Pi2, NIL-Pi9, and NIL-Pizt decreased significantly compared with the observed seedling blast resistance levels. Specifically, NIL-Pi9 had a seedling blast RF of $95.83 \%$ and a panicle blast RF of $8.33 \%$. Similar to the recurrent parent, NIL-Piz was susceptible to all isolates at the heading stage. No significant differences in panicle blast resistance or RF values for most of the improved NIL correlating with the different provinces were detected at the 0.05 significance level, except for NIL-Pizt, which showed moderate resistance in $\mathrm{ZJ}(\mathrm{RF}, 60 \%)$ and JS (RF, 43.33\%), low resistance in $\mathrm{AH}(\mathrm{RF}$, $30 \%$ ), and was susceptible in HB (Fig. 3C).

NIL resistant in blast nurseries were consistent with resistance in artificial inoculation. The NIL and recurrent parent were evaluated for blast resistance under natural conditions in nurseries with high disease pressure situated in four locations: Xinyi City and Jintan City, JS; Lujiang County, AH; and Changxin County, ZJ. High seedling resistance against $M$. oryzae with natural inoculum was similar to seedling resistance to artificial inoculum for all NIL except NIL-Piz and the recurrent parent, both of which were highly susceptible at all four locations (data not shown). Significant differences $(P \leq 0.05)$ of panicle blast resistance were observed among NIL grown in Xinyi City. The NIL carrying Pigm, Pi40, and Pizt were found to be HR, with resistance scores of 0 to 1 . However, NIL-Pi2 and NIL-Pi9 exhibited an MS phenotype (score 5 to 6), and NIL-Piz was HS, with a score of 8 to 9 , equivalent to the susceptibility level of the recurrent parent 07GY31. Disease severity of the NIL planted in Jintan City was less than in Xinyi City. A high level of resistance was exhibited by NILPi2, NIL-Pigm, and NIL-Pi40, whereas NIL-Pi9 and NIL-Pizt had a resistance score of 2 to 3 . The symptoms of NIL-Piz were severe and showed an HS phenotype similar to that of the recurrent parent 07GY31. NIL-Pigm and NIL-Pi4O grown in Lujiang displayed an HR phenotype; Nil-Pi2, NIL-Pi9, and NIL-Pizt displayed an MS phenotype; and NIL-Piz and the recurrent parent 07GY31 displayed an HS phenotype The resistance patterns observed in Changxing County were similar to those observed in Xinyi County, where NIL-Pigm, NIL-Pi40, and NIL-Pizt showed an HR phenotype, NIL-Pi2 and NIL-Pi9 exhibited an MS phenotype, and NIL-Piz and the recurrent parent 07GY31 showed an HS phenotype (Table 2).

GGE-biplot analysis of the panicle blast resistance for the NIL and recurrent parent revealed that the four field trial locations (E1, E2, E3, and E4) formed one mega-environment. Ranking the NIL based on the "ideal genotype" across environments revealed the genotypes (G) of NIL-Pigm (G2) and NIL-Pi40 (G3) to be the best performing and most stable across locations compared with the recurrent parent $07 \mathrm{GY} 31$ (G7). Furthermore, it can be deduced that most of the NIL were comparatively superior performing and stable across environments based
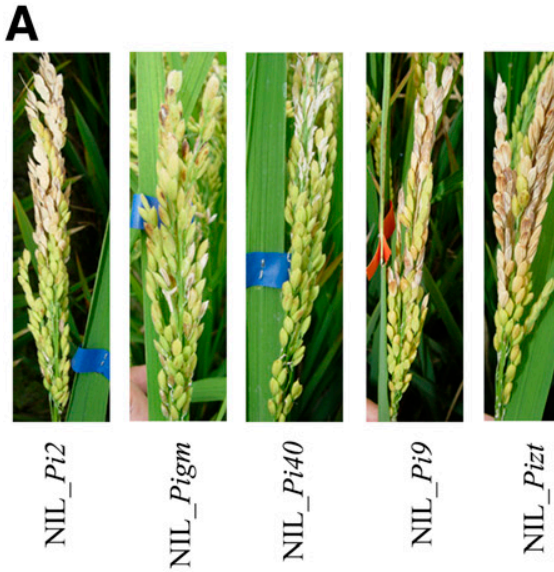

Isolate: JSBY4-3

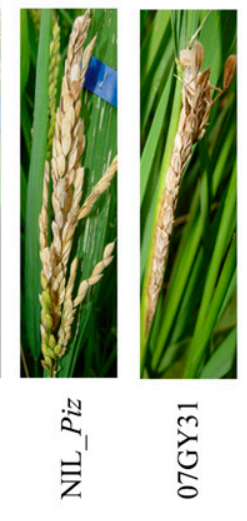

B

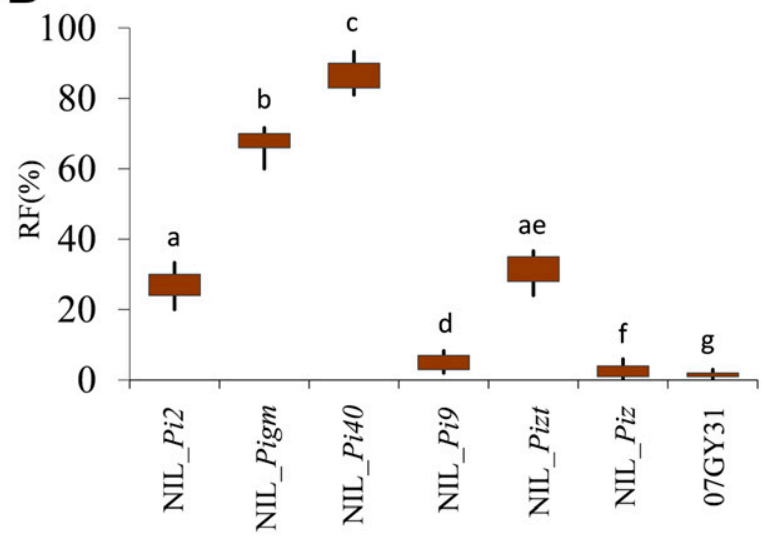

C

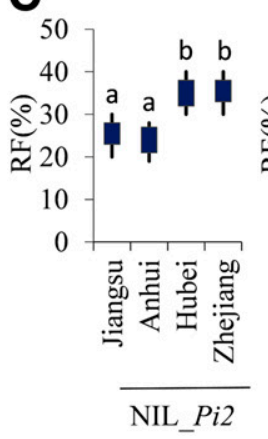

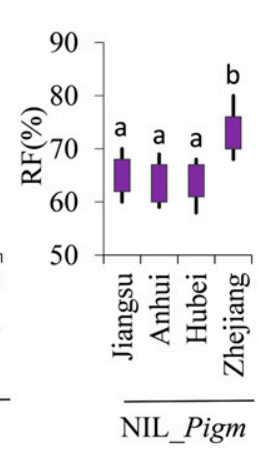
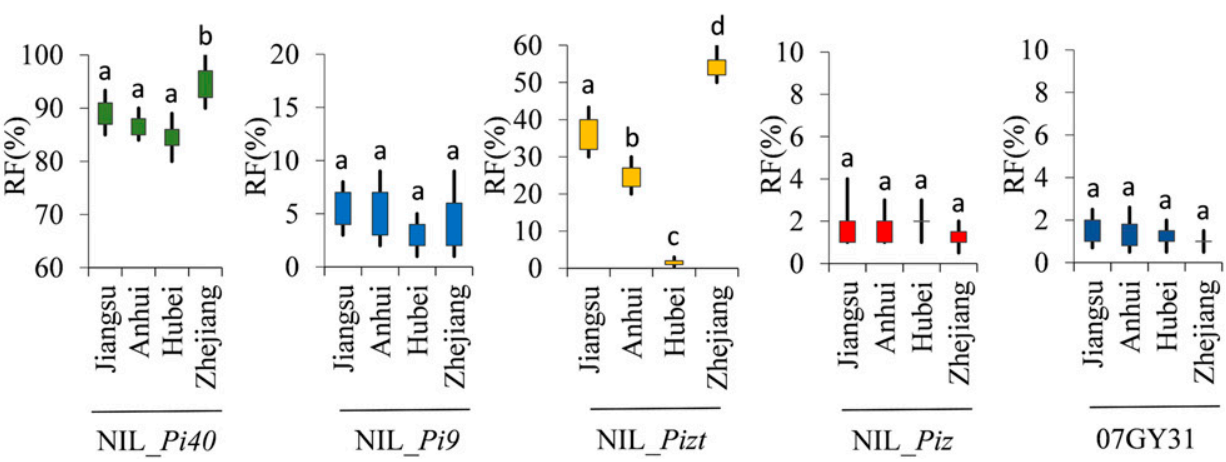

Fig. 3. Disease reaction patterns of improved near-isogenic lines (NIL) and the recurrent parent at the heading stage. A, NIL disease reactions against a typical blast isolate (JSBY4-3) at the heating stage. B, Resistance characterization of improved NIL and the recurrent parent against 60 blast populations. C, Comparison of panicle blast reaction patterns among the improved NIL and the recurrent parent to four Magnaporthe oryzae populations collected in the lower region of the Yangtze River, China. Values labeled with the same letter do not differ significantly according to Tukey's honestly significant difference test at the 0.05 significance level. 
on the position of 07GY31 (G7), except for NIL-Piz (G5), which was relatively equal to $07 \mathrm{GY} 31$ (Fig. 4).

Agronomic and grain quality performance of NIL. Agronomic traits are summarized in Table 3 . There were no significant differences $(P \leq 0.05)$ between NIL with the alleles Pigm, Pi40, Piz, and Pizt, and the recurrent parent for the agronomic traits DFF, PH, PN, TSP, SF, GW, and YPP. However, NIL-Pi2 had a longer DFF and a higher $\mathrm{PH}$ compared with $07 \mathrm{GY} 31$. Additionally, NIL-Pi9 was significantly different $(P \leq 0.05)$ from $07 \mathrm{GY} 31$ on all agronomic traits except for $\mathrm{PN}, \mathrm{SF}$, and GW; the DFF of NIL-Pi9 was less than that of 07GY31; and the PH of NIL-Pi9 was shorter than that of 07GY31. Moreover, the TSP of NIL-Pi9 was less than that of 07GY31; thus, the average YPP of NIL-P $i 9$ was significantly lower than 07GY31.

Table 2. Resistant performance of panicle blast for near-isogenic lines (NIL) and the recurrent parent at four hotspot locations

\begin{tabular}{lcccc}
\hline & \multicolumn{4}{c}{ Disease score $^{\mathbf{z}}$} \\
\cline { 2 - 5 } Genotype & Xinyi & Jintan & Lujiang & Changxin \\
\hline NIL_Pi2 & 6 & 1 & 5 & 6 \\
NIL_Pigm & 1 & 1 & 1 & 1 \\
NIL_Pi40 & 1 & 1 & 1 & 0 \\
NIL_Pi9 & 5 & 3 & 6 & 6 \\
NIL_Piz & 8 & 8 & 9 & 8 \\
NIL_Pizt & 1 & 2 & 5 & 1 \\
07GY31 & 9 & 9 & 9 & 9 \\
\hline
\end{tabular}

${ }^{\mathrm{z}}$ Disease scores: 0 to $1=$ highly resistant, 2 to $3=$ resistant, $4=$ moderately resistant, 5 to $6=$ moderately susceptible, $7=$ susceptible, and 8 to $9=$ highly susceptible.

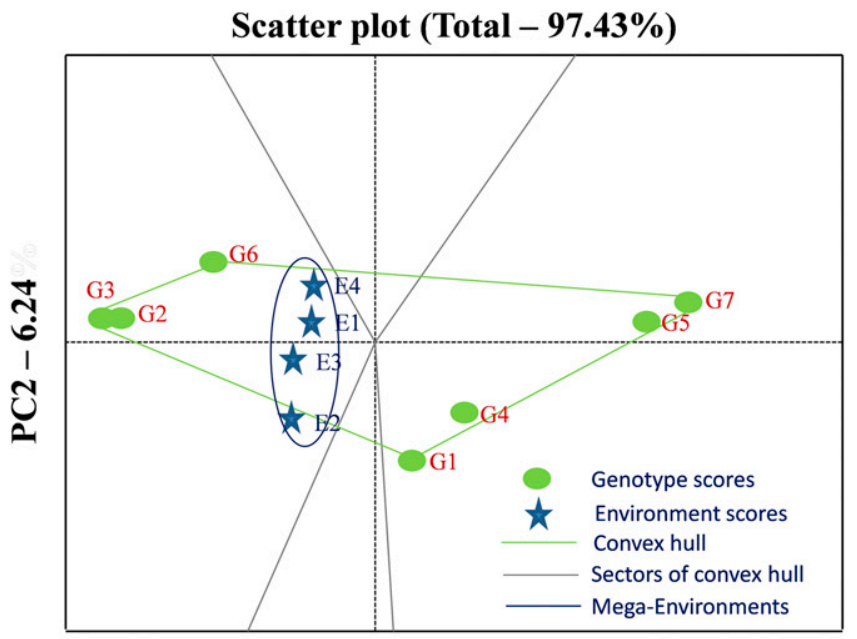

PC1 - 91.20\%

Fig. 4. Scatter diagram of genotype + genotype-environment interaction-biplot analysis depicting mega-environments and resistance performance of near-isogenic lines (NIL) and the recurrent parent across four field locations. E1 $=$ Xinyi, E2 = Jintan, E3 = Lujiang, E4 = Changxin, G1 = NIL_Pi2, G2 = NIL_Pigm, G3 = NIL_Pi40, G4 $=$ NIL_Pi9, G5 $=$ NIL_Piz, G6 $=$ NIL_Pizt, and G7 $=07$ GY31.
Evaluation of results of the grain quality traits for the NIL and 07GY31 are presented in Table 4 . There were no significant differences in most grain quality traits, indicating that no undesirable quality trait alleles were located in the Piz locus which was introduced into the 07GY31 background.

\section{Discussion}

There is obvious coevolution between rice cultivars and M. oryzae populations, and the resistance of rice cultivars is often lost in a few years because of the high variability in $M$. oryzae populations (Dean et al. 2005). Therefore, understanding the pathogenicity of $M$. oryzae populations in the target regions may help guide rice breeding programs to generate cultivars for specific regions with effective and stable resistance. In this study, 144 monoconidial isolates were divided into eight subgroups and 19 physiological races, indicating that the population structure of the rice blast fungus is significantly diverse and complex in the lower region of the Yangtze River, China. However, spatial distribution analysis of $M$. oryzae populations in JS and ZJ revealed a relatively simple race composition dominated by race $\mathrm{ZG}_{1}$, which appeared at a frequency of 67.86 and $50.00 \%$, respectively. These results were consistent with previous studies (Liu et al. 2010b; Lu et al. 1999). Additionally, in $J S, Z_{1}$ has been detected at a frequency of $>50.00 \%$ since the 1980 s, even as high as $73 \%$ in 2006 (Liu et al. $2010 \mathrm{~b}$ ), indicating a strong, long-term compatibility between the main cultivated rice varieties and $\mathrm{ZG}_{1}$ at this location. Alternatively, no predominant race was detected among the 20 monoconidial isolates collected from each of four counties in $\mathrm{AH}$ and $\mathrm{HB}$ (Table 1). This more diverse $M$. oryzae population composition may have resulted in less effectiveness of $R$ genes, which provide vertical resistance against only a small set of blast isolates. Overall, it appears that the resistance exhibited by available rice cultivars may be insufficient to combat diverse $M$. oryzae populations, making it essential to use new and broad-spectrum $R$ genes to improve the resistance of the main cultivated rice cultivars in the lower region of the Yangtze River.

According to the "gene-for-gene" theory, a specific host $R$ gene recognizes a corresponding pathogen avirulence (Avr) gene through direct or indirect interactions, resulting in a host defense response and disease reaction (Césari et al. 2014; Flor 1971; Jia et al. 2000). The variation in $R$ genes should correspond to the regional distribution patterns of specific pathogenic populations of M. oryzae. Previous studies have demonstrated that different $R$ genes are effective against $M$. oryzae originating from different ecological regions. For example, the Pi2 gene has been widely detected in indica-type accessions from southern China and Southeast Asia (Jiang et al. 2015; Singh et al. 2012) and the Pi9 gene has been detected in indica-type accessions from China and the Philippines (Wu et al. 2015a). Similarly, we also found that the $R$ genes $P i 2$ and $P i 9$ in indica-type accessions were effective against rice blast isolates from southern China (Wu et al. 2016). However, in the japonica background used in this study, these $R$ genes were not found to be effective against $M$. oryzae isolates originating from the lower region of the Yangtze River. In particular, $\mathrm{Pi} 9$ merely showed panicle blast RF values of $8.33 \%$ when introduced into the japonica background. In contrast, the $R$ gene Pigm was found to show effective broad-spectrum resistance, with a panicle blast RF value of $71.67 \%$ in japonica background, similar to its RF value of $80 \%$ in indica background (Wu et al. 2016). In our study, Pi40 was found to

Table 3. Agronomic performance of near-isogenic lines (NIL) with different alleles of Piz locus and the recurrent parent ${ }^{2}$

\begin{tabular}{|c|c|c|c|c|c|c|c|}
\hline Lines & DFF (days) & PH (cm) & PN & TSP & SF (\%) & GW (g) & YPP (g) \\
\hline NIL-Pi2 & $99.5 \mathrm{a}$ & $102.4 \mathrm{a}$ & $10.5 \mathrm{a}$ & $123.4 \mathrm{bc}$ & $94.6 \mathrm{a}$ & $26.2 \mathrm{a}$ & $32.11 \mathrm{ab}$ \\
\hline NIL-Pigm & $96.0 \mathrm{~b}$ & $97.8 \mathrm{~b}$ & $10.7 \mathrm{a}$ & $128.2 \mathrm{a}$ & $93.1 \mathrm{a}$ & $26.5 \mathrm{a}$ & $33.84 \mathrm{a}$ \\
\hline NIL-Pi4O & $95.5 \mathrm{~b}$ & $98.2 \mathrm{~b}$ & $10.8 \mathrm{a}$ & $125.4 \mathrm{ab}$ & $94.3 \mathrm{a}$ & $26.8 \mathrm{a}$ & $33.95 \mathrm{a}$ \\
\hline NIL-Pi9 & $90.5 \mathrm{c}$ & $92.7 \mathrm{c}$ & $9.8 \mathrm{a}$ & $118.4 \mathrm{c}$ & $90.3 \mathrm{c}$ & $25.9 \mathrm{a}$ & $27.14 \mathrm{c}$ \\
\hline NIL-Piz & $96.5 \mathrm{~b}$ & $96.8 \mathrm{~b}$ & $10.3 \mathrm{a}$ & $122.5 \mathrm{bc}$ & $91.8 \mathrm{~b}$ & $26.2 \mathrm{a}$ & $30.48 \mathrm{bc}$ \\
\hline NIL-Pizt & $96.5 \mathrm{~b}$ & $98.4 \mathrm{~b}$ & $10.4 \mathrm{a}$ & $126.8 \mathrm{ab}$ & $93.8 \mathrm{a}$ & $26.7 \mathrm{a}$ & $33.03 \mathrm{a}$ \\
\hline 07GY31 & $95.5 \mathrm{~b}$ & $97.2 \mathrm{~b}$ & $10.3 \mathrm{a}$ & $125.5 \mathrm{ab}$ & $92.0 \mathrm{~b}$ & $26.4 \mathrm{a}$ & $31.60 \mathrm{ab}$ \\
\hline
\end{tabular}

${ }^{\mathrm{z}} \mathrm{DFF}=$ days to $50 \%$ flowering, $\mathrm{PH}=$ plant height, $\mathrm{PN}=$ panicle number per plant, $\mathrm{TSP}=$ total spikelets per plant, $\mathrm{SF}=$ spikelet fertility, $\mathrm{GW}=1,000$-grain weight, and YPP = yield per plant. Different letters in the same column shows the significance difference at the 0.05 level. 
Table 4. Grain quality traits of near-isogenic lines (NIL) with multialleles of Piz locus and the recurrent parent ${ }^{\mathrm{z}}$

\begin{tabular}{|c|c|c|c|c|c|c|c|c|c|}
\hline NIL & $\operatorname{BRR}(\%)$ & MRR & RGL & $\mathbf{L} / \mathbf{W}$ & $\mathrm{AC}(\%)$ & CHR & CHD & GC & ADV \\
\hline NIL-Pi2 & $85.3 \mathrm{a}$ & $72.3 \mathrm{a}$ & $4.9 \mathrm{a}$ & $1.8 \mathrm{a}$ & $16.5 \mathrm{a}$ & $41 \mathrm{~b}$ & $4.0 \mathrm{a}$ & $83.2 \mathrm{a}$ & $6.4 \mathrm{a}$ \\
\hline NIL-Pigm & $84.1 \mathrm{a}$ & $72.6 \mathrm{a}$ & $5.3 \mathrm{a}$ & $1.7 \mathrm{a}$ & $15.5 \mathrm{a}$ & $41 \mathrm{~b}$ & $4.1 \mathrm{a}$ & $82.7 \mathrm{a}$ & $6.8 \mathrm{a}$ \\
\hline NIL-Pi40 & $83.7 \mathrm{a}$ & $72.4 \mathrm{a}$ & $5.1 \mathrm{a}$ & $1.8 \mathrm{a}$ & $16.2 \mathrm{a}$ & $44 \mathrm{a}$ & $4.0 \mathrm{a}$ & $78.9 \mathrm{~b}$ & $6.6 \mathrm{a}$ \\
\hline NIL-Pi9 & $85.6 \mathrm{a}$ & $73.3 \mathrm{a}$ & $4.8 \mathrm{a}$ & $1.8 \mathrm{a}$ & $17.1 \mathrm{a}$ & $41 \mathrm{~b}$ & $4.0 \mathrm{a}$ & $81.7 \mathrm{a}$ & $6.7 \mathrm{a}$ \\
\hline NIL-Piz, & $84.5 \mathrm{a}$ & $72.6 \mathrm{a}$ & $5.2 \mathrm{a}$ & $1.7 \mathrm{a}$ & $16.8 \mathrm{a}$ & $44 \mathrm{a}$ & $4.1 \mathrm{a}$ & $78.9 \mathrm{~b}$ & $6.8 \mathrm{a}$ \\
\hline NIL-Pizt & $84.8 \mathrm{a}$ & $72.7 \mathrm{a}$ & $4.9 \mathrm{a}$ & $1.8 \mathrm{a}$ & $16.2 \mathrm{a}$ & $45 \mathrm{a}$ & $4.3 \mathrm{a}$ & $81.5 \mathrm{a}$ & $6.5 \mathrm{a}$ \\
\hline 07GY31 & $83.8 \mathrm{a}$ & $72.8 \mathrm{a}$ & $5.1 \mathrm{a}$ & $1.8 \mathrm{a}$ & $16.9 \mathrm{a}$ & $40 \mathrm{~b}$ & $4.0 \mathrm{a}$ & $82.4 \mathrm{a}$ & $6.4 \mathrm{a}$ \\
\hline
\end{tabular}

${ }^{\mathrm{z}} \mathrm{BRR}=$ brown rice rate, $\mathrm{MRR}=$ milled rice recovery, $\mathrm{RGL}=$ rice grain length, $\mathrm{L} / \mathrm{W}=$ grain length-to-width ratio, $\mathrm{AC}=$ amylose content, $\mathrm{CHR}=$ chalkiness rate,

$\mathrm{CHD}=$ chalkiness degree, $\mathrm{GC}=$ gel consistency, and $\mathrm{ADV}=$ alkali digestion value. Different letters in the same column shows the significance difference at the 0.05 level.

be the most effective, with broad-spectrum resistance against $M$. oryzae isolates from the lower region of the Yangtze River and panicle blast RF values of $93.33 \%$ when introgressed into the japonica background. On the other hand, Pi40 was reported to exhibit a panicle blast RF value of only $40 \%$ in an indica background (Wu et al. 2016). Therefore, these two genes (Pigm and Pi40) could be incorporated into elite japonica cultivars that were released in the lower region of the Yangtze River such as 'Huaidao 5', 'Ning 9108', 'Yangjing 4227', 'Wuyuning 24', and others using MABB. Additionally, we noted that the improved line carrying Pizt exhibited moderate resistance against isolates of $M$. oryzae collected from $\mathrm{ZJ}$ and $\mathrm{JS}$ and low resistance in $\mathrm{AH}$, and was susceptible in HB by artificial inoculation at the heading stage (Fig. 3C). Accordingly, NIL-Pizt showed high resistance in blast nurseries in ZJ and JS and moderate susceptibility in Lujiang County, AH where disease pressure was high (Table 2). This may be because the population structure of $M$. oryzae has a high degree of genetic diversity and the distribution of the physiological races of $M$. oryzae varies with climatic conditions and farming methods in different regions. It is likely that AvrPizt occurs universally in field isolates in ZJ and JS and that the frequency of $A v r$ Pizt in populations from $\mathrm{AH}$ and $\mathrm{HB}$ is relatively low. This is consistent with the finding that $M$. oryzae race composition is relatively homogeneous in $\mathrm{ZJ}$ and $\mathrm{JS}$ and diverse in AH and HB (Table 1). Therefore, Pizt was found to have a region-specific resistance in $\mathrm{ZJ}$ and $\mathrm{JS}$ and could be deployed to breed lines in the target regions.

Blast disease caused by $M$. oryzae mainly occurs in two forms: seedling blast and panicle blast. Owing to challenges associated with studying panicle blast resistance, including the difficult nature of inoculating rice panicles, most researches have focused on seedling blast resistance. Among the approximately 100 blast $R$ genes and 350 quantitative trait loci identified (Ballini et al. 2008; Sharma et al. 2012), only Pb1, Pi64, and qPbml1 display panicle blast resistance (Hayashi et al. 2010; Ishihara et al. 2014; Ma et al. 2015). Among them, $P b 1$ showed a weak correlation between levels of seedling blast resistance and panicle blast resistance (Hayashi et al. 2010), whereas Pi64 exhibited a strong correlation between levels of seedling blast resistance and panicle blast resistance (Ma et al. 2015). However, phenotypic analyses revealed no correlation between panicle blast resistance and seedling blast resistance for $q$ Pbm11 (Ishihara et al. 2014). In this study, NIL-Pigm and NIL-Pi40 showed outstanding resistance to seedling blast and effective resistance against panicle blast, with panicle blast RF values of 71.67 and $93.33 \%$, respectively. NIL-Piz showed the lowest seedling blast, with RF of $21.53 \%$ and was susceptible to all of the isolates at heading stage. However, NIL-Pi2, NIL-Pi9, and NIL-Pizt had a seedling blast RF > $93.06 \%$, and merely showed panicle blast RF values of $33.3,8.33$, and $36.67 \%$, respectively. These results indicate that the correlation between seedling blast resistance and panicle blast resistance may vary among different $R$ genes. Furthermore, previous studies have suggested that different $R$ genes may mediate different signaling pathways to activate disease-resistant reactions. For example, Pita has been shown to interact with $\operatorname{Ptr}(t)$ to mediate disease resistance signal recognition and transduction in rice (Jia and Martin 2008). Pbl interacts with WRKY45 through its $\mathrm{CC}$ domain to activate resistance via the salicylic acid signaling pathway, which is regulated by the ubiquitin proteasome system (Inoue et al. 2013). It has also been shown that the $R$ gene Pid2 interacts directly with the E3 ligase OsPUB15 to regulate plant cell death and blast disease resistance in rice (Wang et al. 2015). Therefore, we hypothesize that different $R$ genes may interact with the target effectors in different ways and mediate different resistance signaling pathways between seedling blast resistance and panicle blast resistance. This is consistent with our findings that the correlation between seedling blast resistance and panicle blast resistance varied among different $R$ genes, which would explain why previous studies have come to different conclusions regarding the correlation between seedling blast resistance and panicle blast resistance (Ishihara et al. 2014; Puri et al. 2009). Additional studies are warranted to verify this hypothesis and further explain the variation in correlation between seedling and panicle blast resistance exhibited by different $R$ genes.

Marker-assisted selection (MAS) is a highly efficient breeding strategy for introduction of disease $R$ genes from both cultivated and exotic germplasm into adaptive genetic backgrounds across generations. Because the donor and the recipient are improved genotypes, both genotypes may be sharing several segments of the genome and some desirable traits such as agronomic and grain quality characters. However, if the donor parent used is a native landrace, the linkage drag problem may be compounded (Stam and Zeven 1981). This is because some genes associated with undesirable traits are tightly linked with $R$ genes on the rice genome (Fukuoka et al. 2009), and some of these genes interact directly with $R$ genes to regulate yield and resistance traits (Deng et al. 2017). In our study, three donor parents were landraces (Pigm, Piz, and Pizt), two were lines derived from wild rice ( $P i 40$ and Pi9), and one was a line bred from a landrace (Pi2). The strategy of deployment with stringent phenotype-based selection coupled with MAS involving both foreground and background selection was adopted in the recurrent backcrossing procedure in this study. Only the plants with agromorphological resemblance to the recurrent parent were advanced to the next generation. After six rounds of backcrossing and four rounds of self-crossing, no apparent agronomic or grain-quality penalty associated with the presence of $R$ genes was noticed in most of the NIL (Tables 3 and 4), except for NIL-Pi9, which possessed less DFF and TSP and shorter PH than the recurrent parent 07GY31. These results indicate that the strategy could accelerate the recovery of the recurrent parent phenotype in a few generations, and could be used in other $R$ gene introductions in breeding practice.

\section{Acknowledgments}

This study was supported by the Key Studying and Developing Project of Jiangsu Province for Modern Agriculture (BE2015355-2, BE2015336), the National Modern Agricultural Industry Technology System Special Fund (CARS-0145), and the National Science Foundation for Young Scientists of Jiangsu Province, China (BK20160447). We thank the editor and two anonymous reviewers for comprehensive and useful comments which have significantly improved the article.

\section{Literature Cited}

Ashkani, S., Rafii, M., Shabanimofrad, M., Ghasemzadeh, A., Ravanfar, S., and Latif, M. 2016. Molecular progress on the mapping and cloning of functional genes for blast disease in rice (Oryza sativa L.): Current status and future considerations. Crit. Rev. Biotechnol. 36:353-367.

Ballini, E., Morel, J. B., Droc, G., Price, A., Courtois, B., Notteghem, J. L., and Tharreau, D. 2008. A genome-wide meta-analysis of rice blast resistance genes and quantitative trait loci provides new insights into partial and complete resistance. Mol. Plant-Microbe Interact. 21:859-868. 
Bradbury, P. J., Zhang, Z., Kroon, D. E., Casstevens, T. M., Ramdoss, Y., and Buckler, E. S. 2007. TASSEL: Software for association mapping of complex traits in diverse samples. Bioinformatics 23:2633-2635.

Candole, B. L., Siebenmorgen, T. J., Lee, F. N., and Cartwright, R. D. 1999. The effect of panicle blast on the physical properties and milling quality of rice cultivar 'M202'. Res. Ser. Ark. Agric. Exp. Stn. 468:142-147.

Césari, S., Kanzaki, H., Fujiwara, T., Bernoux, M., Chalvon, V., Kawano, Y., Shimamoto, K., Dodds, P., Terauchi, R., and Kroj, T. 2014. The NB-LRR proteins RGA4 and RGA5 interact functionally and physically to confer disease resistance. EMBO J. 33:1941-1959.

Chen, Z., Wang, B., Dong, X., Liu, H., Ren, L., Chen, J., Hauck, A., Song, W., and Lai, J. 2014. An ultra-high density bin-map for rapid QTL mapping for tassel and ear architecture in a large $F_{2}$ maize population. BMC Genomics 15:433-442.

Divya, B., Robin, S., Rabindran, R., Senthil, S., Raveendran, M., and Joel, A. J. 2014. Marker assisted backcross breeding approach to improve blast resistance in Indian rice (Oryza sativa) variety ADT43. Euphytica 200:61-77.

Dean, R. A., Talbot, N. J., Ebbole, D. J., Farman, M. L., Mitchell, T. K., Orbach, M. J., Thon, M., Kulkarni, R., Xu, J. R., Pan, H., Read, N. D., Lee, Y. H., Carbone, I., Brown, D., Oh, Y. Y., Donofrio, N., Jeong, J. S., Soanes, D. M., Djonovic, S., Kolomiets, E., Rehmeyer, C., Li, W., Harding, M., Kim, S., Lebrun, M. H., Bohnert, H., Coughlan, S., Butler, J., Calvo, S., Ma, L. J., Nicol, R., Purcell, S., Nusbaum, C., Galagan, J. E., and Birren, B. W. 2005. The genome sequence of the rice blast fungus Magnaporthe grisea. Nature 434:980-986.

Deng, J. P., and Du, Y. L. 2006. Status and development countermeasures of japonica rice production in Jiangsu Province. China Rice. 4:8-11.

Deng, Y., Zhai, K., Xie, Z., Yang, D., Zhu, X., Liu, J., Wang, X., Qin, P., Yang, Y., Zhang, G., Li, Q., Zhang, J., Wu, S., Milazzo, J., Mao, B., Wang, E., Xie, H., Tharreau, D., and He, Z. 2017. Epigenetic regulation of antagonistic receptors confers rice blast resistance with yield balance. Science 355:962-965.

Ellur, R. K., Khanna, A., Yadav, A., Pathania, S., Rajashekara, H., Singh, V. K., Gopala Krishnan, S., Bhowmick, P. K., Nagarajan, M., Vinod, K. K., Prakash, G., Mondal, K. K., Singh, N. K., Vinod Prabhu, K., and Singh, A. K. 2016. Improvement of Basmati rice varieties for resistance to blast and bacterial blight diseases using marker assisted backcross breeding. Plant Sci. 242:330-341.

Fan, F. J., Wang, F. Q., Liu, Y. F., Wang, J., Zhu, J. Y., Li, W. Q., Zhong, W. G., and Yang, J. 2014. Evaluation of resistance to rice panicle blast with resistant genes Pi-b, Pi-ta, Pikm and Pi54. Acta Agric. Boreali-Occident. Sin. 29:221-226.

Flor, H. H. 1971. Current status of the gene-for-gene concept. Annu. Rev. Phytopathol. 9:275-296.

Fukuoka, S., Saka, N., Koga, H., Ono, K., Shimizu, T., Ebana, K., Hayashi, N., Takahashi, A., Hirochika, H., Okuno, K., and Yano, M. 2009. Loss of function of a proline-containing protein confers durable disease resistance in rice. Science 325:998-1001.

Fukuoka, S., Yamamoto, S. I., Mizobuchi, R., Yamanouchi, U., Ono, K., Kitazawa, N., Yasuda, N., Fujita, Y., Nguyen, T. T. T., and Koizumi, S. 2014. Multiple functional polymorphisms in a single disease resistance gene in rice enhance durable resistance to blast. Sci. Rep. 4:1-7.

Guajardo, V., Solis, S., Sagredo, B., Gainza, F., Munoz, C., Gasic, K., and Hinrichsen, P. 2015. Construction of high density sweet cherry (Prunus avium L.) linkage maps using microsatellite markers and SNPs detected by genotyping-by-sequencing (GBS). PLoS One 10:e0127750.

Hayashi, N., Inoue, H., Kato, T., Funao, T., Shirota, M., Shimizu, T., Kanamori, H., Yamane, H., Hayano-Saito, Y., Matsumoto, T., Yano, M., and Takatsuji, H. 2010. Durable panicle blast-resistance gene $\mathrm{Pbl}$ encodes an atypical CCNBS-LRR protein and was generated by acquiring a promoter through local genome duplication. Plant J. 64:498-510.

Hao, Z. N., Wang, L. P., Liang, J. E., and Tao, R. X. 2011. Response of the panicles exserted from the caulis and from various effective tillers at four stages of panicle development to neck blast in rice. Eur. J. Plant Pathol. 131:269-275.

He, F., Zhang, H., Liu, J. L., Wang, Z. L., and Wang, G. L. 2014. Recent advances in understanding the innate immune mechanisms and developing new disease resistance breeding strategies against the rice blast fungus Magnaporthe oryzae in rice. Hereditas 36:756-765.

He, H. M., Wu, X. W., Shi, L., Tai, D. L., and Mei, A. Z. 2015. Characters and control countermeasures of rice panicle blast occurrence in Dongtai city in 2014. Mod. Agric. Sci. Technol. 15:157-158.

Inoue, H., Hayashi, N., Matsushita, A., Xinqiong, L., Nakayama, A., Sugano, S., Jiang, C. J., and Takatsuji, H. 2013. Blast resistance of CC-NB-LRR protein $\mathrm{Pb} 1$ is mediated by WRKY45 through protein-protein interaction. Proc. Natl. Acad. Sci. USA 110:9577-9582.

IRRI. 2002. Pages 15-16 in: Standard Evaluation System for Rice (SES), 4th ed. International Rice Research Institute (IRRI), Los Banos, Philippines.

Ishihara, T., Hayano-Saito, Y., Oide, S., Ebana, K., La, N. T., Hayashi, K., Ashizawa, T., Suzuki, F., and Koizumi, S. 2014. Quantitative trait locus analysis of resistance to panicle blast in the rice cultivar Miyazakimochi. Rice 7:2.

Jia, Y., and Martin, R. 2008. Identification of a new locus, $P \operatorname{tr}(t)$, required for rice blast resistance gene Pi-ta-mediated resistance. Mol. Plant-Microbe Interact. 21:396-403.

Jia, Y., McAdams, S. A., Bryan, G. T., Hershey, H. P., and Valent, B. 2000. Direct interaction of resistance gene and avirulence gene products confers rice blast resistance. EMBO J. 19:4004-4014.

Jiang, J., Yang, D., Ali, J., and Mou, T. 2015. Molecular marker-assisted pyramiding of broad-spectrum disease resistance genes, $\mathrm{Pi2}$ and $\mathrm{Xa23}$, into GZ63-4S, an elite thermo-sensitive genic male-sterile line in rice. Mol. Breed. 35:83.
Khush, G. S., and Jena, K. 2009. Current status and future prospects for research on blast resistance in rice (Oryza sativa L.). Pages 1-10 in: Advances in Genetics, Genomics and Control of Rice Blast Disease. G.-L. Wang and B. Valent, eds. Springer, Dordrecht, The Netherlands.

Koide, Y., Kobayashi, N., Xu, D., and Fukuta, Y. 2009. Resistance genes and selection DNA markers for blast disease in rice (Oryza sativa L.). Jpn. Agric. Res. Q. 43:255-280.

Li, H., and Durbin, R. 2009. Fast and accurate short read alignment with BurrowsWheeler transform. Bioinformatics 25:1754-1760.

Ling, Z. Z., Lei, C. L., and Wang, J. L. 2004. Review and prospect for study of physiologic races on rice blast fungus (Pyricularia grisea). Sci. Agric. Sin. 37:1849-1859.

Liu, J., Wang, X., Mitchell, T., Hu, Y., Liu, X., Dai, L., and Wang, G. L. 2010a Recent progress and understanding of the molecular mechanisms of the riceMagnaporthe oryzae interaction. Mol. Plant Pathol. 11:419-427.

Liu, Y. F., Chen, Z. Y., Liu, Y. Z., Luo, C. P., Nie, Y. F., Yu, J. J., Wang, X. Y., and Yin, X. L. 2010b. Changes of Magnaporthe oryzae population in Jiangsu Province from 2001 to 2010. Jiangsu J. Agric. Sci. 26:1233-1237.

Lu, F., Wang, F. M., Zheng, X. B., Shi, A. B., Chen, Y. L., and Chen, Z. Y. 1999 Interrelationship between race evolution of Magnaporthe grisea and rice cultivars in Jiangsu Province. J. Nanjing Agric. Univ. 22:31-34.

Lu, Y. J., and Zheng, K. L. 1992. A simple method for extracting rice DNA. Chin. J. Rice Sci. 6:47-48.

Ma, J., Lei, C., Xu, X., Hao, K., Wang, J., Cheng, Z., Ma, X., Zhou, K., Zhang, X., Guo, X., Wu, F., Lin, Q., Wang, C., Zhai, H., Wang, H., and Wan, J. 2015. Pi64, Encoding a novel CC-NBS-LRR protein, confers resistance to leaf and neck blast in rice. Mol. Plant-Microbe Interact. 28:558-568.

Mackill, D., and Bonman, J. 1992. Inheritance of blast resistance in near-isogenic lines of rice. Phytopathology 82:746-749.

Pinnschmidt, H. O., Teng, P. S., and Yong, L. 1994. Methodology for quantifying rice yield effects of blast. Pages 381-408 in: Rice Blast Disease. R. S. Zeigler, P. S. Teng, and S. A. Leong, eds. CAB International, Wallingford, UK in association with IRRI, Manila, Philippines.

Poland, J. A., Brown, P. J., Sorrells, M. E., and Jannink, J. L. 2012. Development of high-density genetic maps for barley and wheat using a novel two-enzyme genotyping-by-sequencing approach. PLoS One 7:e32253.

Puri, K. D., Shrestha, S. M., Chhetri, G. B. K., and Joshi, K. D. 2009. Leaf and neck blast resistance reaction in tropical rice lines under green house condition. Euphytica 165:523-532.

Sharma, T., Rai, A., Gupta, S., Vijayan, J., Devanna, B., and Ray, S. 2012. Rice blast management through host-plant resistance: Retrospect and prospects. Agric. Res. 1:37-52.

Singh, A. K., Singh, V. K., Singh, A., Ellur, R. K., Pandian, R., Krishnan, S. G. Singh, U., Nagarajan, M., Vinod, K., and Prabhu, K. 2015. Introgression of multiple disease resistance into a maintainer of Basmati rice CMS line by marker assisted backcross breeding. Euphytica 203:97-107.

Singh, V. K., Singh, A., Singh, S., Ellur, R. K., Choudhary, V., Sarkel, S., Singh, D., Krishnan, S. G., Nagarajan, M., and Vinod, K. 2012. Incorporation of blast resistance into "PRR78", an elite Basmati rice restorer line, through marker assisted backcross breeding. Field Crops Res. 128:8-16.

Sirithunya, P., Tragoonrung, S., Vanavichit, A., Pa-In, N., Vongsaprom, C., and Toojinda, T. 2002. Quantitative trait loci associated with leaf and neck blast resistance in recombinant inbred line population of rice (Oryza sativa). DNA Res. 9:79-88.

Stam, P., and Zeven, A. C. 1981. The theoretical proportion of the donor genome in near isogenic lines of self-fertilizers bred by backcrossing. Euphytica 30: 227-238.

Su, J., Wang, W., Han, J., Chen, S., Wang, C., Zeng, L., Feng, A., Yang, J., Zhou, B. and Zhu, X. 2015. Functional divergence of duplicated genes results in a novel blast resistance gene Pi50 at the Pi2/9 locus. Theor. Appl. Genet. 128:2213-2225.

Thruston, H. D. 1998. Pages 31-40 in: Tropical Plant Diseases, 2nd ed. American Phytopathological Society, St. Paul, MN.

Titone, P., Mongiano, G., and Tamborini, L. 2015. Resistance to neck blast caused by Pyricularia oryzae in Italian rice cultivars. Eur. J. Plant Pathol. 142:49-59.

Wang, J., Qu, B., Dou, S., Li, L., Yin, D., Pang, Z., Zhou, Z., Tian, M., Liu, G., and Xie, Q. 2015. The E3 ligase OsPUB15 interacts with the receptor-like kinase PID2 and regulates plant cell death and innate immunity. BMC Plant Biol. 15:49.

Wei, F., and Song, Z. D. 2014. Characters and control countermeasures of rice panicle blast occurrence in Ganyu city in 2014. Mod. Agric. Sci. Technol. 24:147-149.

Wu, J., Kou, Y., Bao, J., Li, Y., Tang, M., Zhu, X., Ponaya, A., Xiao, G., Li, J., Li, C., Song, M. Y., Cumagun, C. J., Deng, Q., Lu, G., Jeon, J. S., Naqvi, N., and Zhou, B. 2015a. Comparative genomics identifies the Magnaporthe oryzae avirulence effector AvrPi9 that triggers Pi9-mediated blast resistance in rice. New Phytol. 206:1463-1475.

Wu, Y., Xiao, N., Yu, L., Pan, C., Li, Y., Zhang, X., Liu, G., Dai, Z., Pan, X., and Li, A. 2015b. Combination patterns of major $R$ genes determine the level of resistance to the $M$. oryzae in rice (Oryza sativa L.). PLoS One 10 e0126130.

Wu, Y. Y., Yu, L., Pan, C. H., Dai, Z. Y., Li, Y. H., Xiao, N., Zhang, X. X., Ji, H. J., Huang, N. S., Zhao, B. H., Zhou, C. H., Liu, G. Q., Liu, X. J., Pan, X. B., Liang, C. Z., and Li, A. H. 2016. Development of near-isogenic lines with different alleles of Piz locus and analysis of their breeding effect under Yangdao 6 background. Mol. Breed. 36:12. 
Xu, X., Hayashi, N., Wang, C. T., Fukuoka, S., Kawasaki, S., Takatsuji, H., and Jiang, C. J. 2014. Rice blast resistance gene Pikahei-1 (t), a member of a resistance gene cluster on chromosome 4, encodes a nucleotide-binding site and leucine-rich repeat protein. Mol. Breed. 34:691-700.

Yan, W. K. 2010. Optimal use of biplots in analysis of multi-location variety test data. Acta Agron. Sin. 36:1805-1819.

Yu, M. M., Dai, Z. Y., Pan, C. H., Chen, X. J., Yu, L., Zhang, X. X., Li, Y. H., Xiao, N., Gong, H. B., Sheng, S. L., Pan, X. B., Zhang, H. X., and Li, A. H. 2013. Resistance spectrum difference between two broad-spectrum blast resistance genes, Pigm and $P i 2$, and their interaction effect on Pil. Acta Agron. Sin. 39:1927-1934.

Zhang, L. N., Cao, G. L., and Han, L. Z. 2012. Analysis of genetic diversity of japonica rice landrace in China with microsatellite marker. Sci. Agric. Sin 45:405-413.

Zhang, Z. J., Zhang, H. X., Yang, J. C., Song, Y. S., Zhao, B. H., Ji, H. J., and Zhu, Q. S. 2011. Changes of safe dates for full heading in japonica rice over past 50 years in Jiangsu Province. Acta Agron. Sin. 37:146-151. 